\title{
Uterine Fibroids: A Ten Year Clinical Review in Ile-Ife, Nigeria
}

\author{
Alexander T. Owolabi,' Babalola Bakare,, Oluwafemi Kuti' \& Olabisi M. Loto' \\ 'Department of Obstetrics, Gynaecology \& Perinatology, Obafemi Awolowo University \& \\ ${ }^{2}$ Department of Obstetrics and Gynaecology, Obafemi Awolowo University Teaching Hospitals Complex, \\ Ile-Ife, Osun State, Nigeria
}

\begin{abstract}
Objectives: The study is a ten year retrospective review to determine the incidence, clinical presentation and mode of management of uterine leiomyoma (fibroids) at the Obafemi Awolowo University Teaching Hospital, Ile-Ife, Nigeria.

Methods: The data from all case notes of histologically confirmed cases of uterine fibroids managed at the Ife state Hospital, Ile-Ife, from January 15t, 1999 to December $31^{\text {st }} 2008$ formed the basis of this study. Information related to the demography, clinical features, mode of treatment and complications were collected and analysed.

Results: During the period studied, there were 4444 gynaecological admissions and 320 cases of uterine leiomyoma (fibroids) giving an incidence of $7.20 \%$ of all gynaecological admissions. Majority (67.81\%) of the patient was 30-49 years old and $60 \%$ were of low parity $(0-2)$. Common presenting features were menstrual disorders (66.88\%), abdominal swelling (45\%), abdominal pain (33.10\%), infertility (30\%) and anaemia (30\%). Uterine size at presentation was greater than twelve weeks in $76.56 \%$ of cases. The operative treatment involves hysterectomy in 35\% of cases while myomectomy was done in $65 \%$ of cases. The common post-operative complications were pyrexia (10\%), Anaemia (8.12\%) and wound infection (5.32\%).

Conclusions: Late presentation of patients makes the fibroids to be huge and complicated with symptoms before they were diagnosed. It is advisable that women in the reproductive age group should be periodically examined to detect this growth earlier. This will prevent various complications recorded in this study. Surgery remains the main mode of management in our environment.
\end{abstract}

Key words: Uterine Leiomyoma, Fibroids, Presentations, Management.

\section{Introduction}

Uterine leiomyomata also called uterine fibroids or simply myoma is a benign tumour of the uterus, the commonest neoplasia of the female genital tract ${ }^{1-5}$. It is estimated that about $20-30 \%$ of women over 30 years of age harbour this tumour although most are symptomless $^{5-6}$. Several reports put the incidence between $50-70 \%$ of autopsy and hysterectomy specimens ${ }^{2,5-7}$. In the tropics, it has been said that gynaecological operation list is not complete without the operation of uterine fibroids.
The causes of uterine fibroid remain largely unknown but several factors have been associated with it. It is commoner in the Negroid race than the Caucasians and the incidence is higher in nulliparous, infertile and obese women. Prolonged use of oral contraceptive pill and increasing number of term pregnancies protects against the development of uterine fibroid ${ }^{5-10}$.

Mode of management of uterine fibroids includes conventional and laparoscopic myomectomy and hysterectomy and uterine artery embolisation; while

Corresspondence

Dr. Alexander T. Owolabi

Department of Obstetrics, Gynecology and Perinatology,

College of Health Sciences, Obafemi Awolowo University,

Ile Ife, Osun State, Nigeria

Tel: +234803 7151125 .

FAX 234-36-230-705

Email:alexandrerowolabi@yahoo.com 
gonadotrophin releasing hormone agonist $(\mathrm{GnRH}$ agonist) is used to suppressed big fibroids before surgical intervention ${ }^{5,6,11,12}$.

This retrospective study was designed to determine the incidence, clinical presentation and mode of management of uterine fibroids in Ife State Hospital, Ile-Ife, Osun State, Nigeria.

\section{Methods}

All cases of uterine fibroids over the ten years period from January $1^{\text {st }}, 1999$ to December $31^{\text {st }}, 2008$ were retrieved from Medical Records Department of Ife State Hospital, an arm of Obafemi Awolowo University Teaching Hospitals Complex, Ile-Ife, Nigeria. There were 328 patients operated for uterine fibroid but only the 320 histologically confirmed cases of uterine fibroid were used for the analysis. The case notes were studied and data related to the patients' age, parity occupation, clinical features, mode of treatment and complications were collected and analysed. During the period under review, all the patients were admitted after obtaining a full history and physical examination. Various investigations were performed as indicated and different types of surgical treatment were used. Postoperative care was as usual for a major abdominal surgery.

\section{Results}

There were 4444 gynaecological admissions during the periods of study among which were 320 confirmed cases of uterine fibroid. This represents $7.20 \%$ of all gynaecological admissions. The age of the patient ranged from 23 to 51 years with a mean age of $35.0 \pm-1.6$ years. The highest proportion of cases of uterine fibroids occurred in the age range of 30-39 years that accounted for $129[40.31 \%$ ] of cases. Patients aged 3049 years accounted for $217[67.81 \%]$ of the total.

The parity of the patients ranged from 0 to 7 with a mean parity of 2.4 \pm-1.3 . Nullipara accounted for 77 $(24.06 \%)$ of the cases and $61(19.06 \%)$ were para 1 . Majority were para2 and below $192(60.0 \%)$ while 42 (13.12\%) were grandmultipara (para5 and above).

The presentations of cases of uterine fibroids are shown in table I. Most of the patients presented with multiple features while the commonest complaints were menstrual disturbances [66.88\%], abdominal swelling [45\%], abdominal pain [33.12\%] and infertility [30\%]. Other symptoms patients presented with were anaemia (packed cell volume $<30 \%$ ) [30\%], recurrent abortion [24.69\%], hypertension [16.56\%] and dysmenorrhoea [11.88\%]. Majority, 192[60\%], of the patients presented with uterine sizes ranging from 12 to 20 weeks, $75[23.44 \%]$ presented with uterine sizes $<12$ weeks while uterine sizes ranging from $>20$ to 32 weeks formed $36[11.25 \%]$ of the cases and $17[5.31 \%]$ of the patients had uterine sizes $>32$ weeks. The majority $263[82.19 \%]$ of patients in this series had multiple fibroids, the highest number being 24 fibroid nodules. The commonest site where the fibroid are located in this series was intramural [54.37\%], sub serous [24.37\%], sub mucous [18.12\%] and in the broad and round ligaments [3.12\%].

Table 1. Mode of presentation of patients with uterine fibroids at Ife State Hospital, Ile-Ife, Nigeria.

\begin{tabular}{llrr}
\hline Presentation & Number & $\mathbf{\%}$ \\
\hline 1 Menstrual abnormalities & 214 & 66.88 \\
& - Menorrhagia & 127 & 39.69 \\
& -Irregular menses & 87 & 27.19 \\
2 & Lower abdominal swelling & 144 & 45.00 \\
3. & Lower abdominal pain & 106 & 33.12 \\
4. Infertility & 96 & 30.00 \\
& - Primary Infertility & 65 & 20.31 \\
& -Secondary Infertility & 31 & 9.69 \\
5 & Anaemia (PCV <30\%) & 96 & 30.00 \\
6 & Recurrent abortions & 79 & 24.69 \\
7 & Hypertension (blood & & \\
& pressure $>140 / 90 \mathrm{mmHg})$ & 53 & 16.56 \\
8 & Dysmenorrhoea & 38 & 11.88 \\
\hline
\end{tabular}

Table 2. Operations performed on the patients with uterine fibroids at Ife State Hospital, lle-lfe, Nigeria.

\begin{tabular}{|c|c|c|c|}
\hline \multicolumn{2}{|c|}{ Types of Operation } & \multirow{2}{*}{$\begin{array}{r}\text { Number } \\
59\end{array}$} & \multirow{2}{*}{$\begin{array}{r}\% \\
18.44\end{array}$} \\
\hline 1 & $\begin{array}{l}\text { Total Abdominal Hysterectomy } \\
\text { with bilateral salpingo } \\
\text { - Oophorectomy (TAH \& BSO) }\end{array}$ & & \\
\hline 2 & $\begin{array}{l}\text { Total Abdominal Hysterectomy } \\
\text { (TAH) only }\end{array}$ & 33 & 10.31 \\
\hline 3 & TAH \& Unilateral salphingo & & \\
\hline & -Oophorectomy & 10 & 3.12 \\
\hline 4 & Subtotal Hysterectomy only & 5 & 1.56 \\
\hline 5 & Vaginal hysterectomy only & 5 & 1.56 \\
\hline 6 & Abdominal myomectomy only & 120 & 37.50 \\
\hline 7 & $\begin{array}{l}\text { Myomectomy + Tuboplasty/ } \\
\text { Adhesiolysis }\end{array}$ & 62 & 19.38 \\
\hline 8 & $\begin{array}{l}\text { Myomectomy + Unilateral } \\
\text { Cystectomy }\end{array}$ & 26 & 8.13 \\
\hline
\end{tabular}

Table 3. Postoperative morbidity recorded in cases of uterine fibroids at Ife State Hospital, Ile-Ife, Nigeria.

\begin{tabular}{llrr}
\hline Morbidity & Number & \% \\
\hline 1 & Pyrexia & 32 & 10.00 \\
2 & Anaemia & 26 & 8.12 \\
3 & Wound infection & 17 & 5.32 \\
4 & Vault infection & 1 & 0.3 \\
5 & Pelvic abscess & 1 & 0.3 \\
6 & Wound dehiscence & 1 & 0.3 \\
\hline
\end{tabular}


The types of operative procedure performed were shown in table II. Hysterectomy was done in 112 $(35.0 \%)$ cases while myomectomy was done in 208 $(65.0 \%)$ cases.

The postoperative complications as shown in Table III, occurred in 78[24.37\%], Pyrexia occurred in 32[10\%] of cases while anaemia (packed cell volume of less than $30 \%$ ) was recorded in $26[8.12 \%]$ of cases and blood transfusion was required in $22[6.87 \%]$ of cases.

The range of duration of postoperative hospital stay varied from 7-16 days with a mean of 8.7 days majority of the patients, $182[56.87 \%]$ stayed for eight days or less, $112[35 \%$ ] stayed for between 10-14 days following surgery and $26[8.12 \%$ ] cases stayed for more than 14 days. There was no death among the cases reviewed.

\section{Discussion}

In this review, uterine fibromyomata accounted for $7.20 \%$ of all gynaecological admissions during the period of study. This is a comparable figure with the reported prevalence of $7.8 \%$ and $8.3 \%$ from Zaria and Ilesa, Nigeria, respectively but less than that obtained in Ilorin and Jamaica $13.4 \%$ and $30 \%$ respectively. ${ }^{8,9,10}$. This help to assess that burden of the disease is high in the community even thou the true incidence in the communities are unknown because majority of cases are asymtomatic $1,5,10,13,14$.

The age distribution of the case studied in this series ranged from 23 to 51 with a mean age of 35.4 years. This finding is in agreement with the observation that majority of patients are found at any age after puberty ${ }^{3}$, 9. Among the Caucasians, uterine fibromyomata tend to occur around the age of 30 years $^{5}$ and commonly cause symptoms between ages 35 and 45 years ${ }^{2}$. Majority $67.5 \%$ of cases presented in the fourth and fifth decades of life; this confirms earlier observation ${ }^{5}$, ${ }^{9}$. Though the reason for high incidence of fibromyomata in the fourth decade of life is speculative, the female sex hormones have been implicated in the aetiology $4,5,8,15$.

Uterine fibroids have been known to be commoner in nulliparous or relatively infertile women ${ }^{2,5,7,10}$. This study also agrees with earlier observation with low parity forming $60 \%$ while nullipara and primipara formed $43.12 \%$ of cases. The observation of a significant number of cases of multiparous women with uterine fibromyomata may be attributed to racial factor. Women of Negroid origin tend to develop fibromyomata despite having had children ${ }^{2,5}$.

Often fibroids are symptomless and the clinical presentation is variable. The incidence of abnormal menstrual bleeding was $66.9 \%$ that is comparable to
$70.4 \%$ reported in Zaria but more than $52.2 \%$ reported in Ilesa, Nigeria ${ }^{9,10}$. The aetiology of increased uterine bleeding is not always clear but has been variously related to hyperplastic endometrium, increased vascularity of the uterus, and functional disturbance in the large oedematous ovaries often found in association with fibroids ${ }^{2,5}$.

The occurrence of infertility (30\%) in this review is less than that reported in Ilorin $(56.1 \%)$ and Ilesa $(50.7 \%)^{8 \text {, }}$ ${ }^{9}$. Fibroids as a causal factor in infertility is still controversial as other factors are usually found at surgery which could account for infertility in most patients ${ }^{8}$. The sub mucous type may block the cornual ends of the uterus or prevent sperm transportation to the uterine tubes. However, more important is the frequent association of chronic pelvic inflammatory disease with fibroids as a cause of infertility ${ }^{3,16}$.

The occurrence of recurrent abortions $24.69 \%$ in this series is in agreement with $23.0 \%$ reported by Emembolu ${ }^{8}$ but lower than $41 \%$ reported by Butram and Reiter ${ }^{16}$. This may be due to the fact that relationship between fibroid and abortion depends on some other unknown factors.

Hypertension was seen in $16.56 \%$ of the cases in this review. This is comparable with $15.5 \%$ reported in Ilesa ${ }^{10}$ but lower than $25.5 \%$ reported in Zaria ${ }^{9}$. Its occurrence may be related to the age of the patients.

Anaemia is a recognised complication of uterine fibroid $^{4,5,6,9,10}$. In this review $30 \%$ of cases were observed to have anaemia. The incidence of anaemia may be due to the fact that many of the patients in our environment already have other factors predisposing to anaemia such as malnutrition, malaria and hookworm infestations ${ }^{8,9}$. Menorrhagia that was found in 39.69\% of cases may then aggravate the already existing anaemic state.

Analysis of the uterine sizes at presentation showed that many of the patients pre-sented with large uterine sizes. In this review fibroid larger than 12 weeks gestation and above accounted for $76.56 \%$ of cases. This is probably due to the fact that patient presented late. Hysterectomy with or without removal of the tube and ovaries was performed in $34.99 \%$ of cases in this series, while myomectomy was done in $65.01 \%$. The proportion of our cases that had myomectomy performed may be related to a concern for future pregnancy in the absence of any other pelvic diseases requiring hysterectomy. Where the fibroids are multiple and large and the women are nearing menopause and symptoms are considerable, hysterectomy is always a better choice ${ }^{8,9,10}$. Simple hysterectomy with conservation of the ovaries that was done in $13.43 \%$ in 
this review was probably to ensure that a state of artificial menopause was not prematurely induced in younger patients. Modern methods of medical and surgical treatment of fibroids such as the use of gonadotrophin releasing hormone agonist ( $\mathrm{GnRH}$ agonist), uterine artery embolisation and laparoscopic or hysteroscopic myomectomy were not available in our unit during the period of review.

Post operative morbidity seen in this review was attributable to pyrexia (10\%) and anaemia (8.12\%). Post operative pyrexia in this review was as result of wound infection, vault infection and malaria infestation. Blood transfusion was required in $6.1 \%$ of the cases as result of blood loss and post operative anaemia. Late presentation of patients makes the fibroids to be huge and complicated with symptoms before they were diagnosed. It is advisable that women in the reproductive age group should be periodically examined to detect this growth earlier. This will prevent various complications recorded in this study.

\section{References}

1. Stewart E. Epidemioloogy, Pathogenesis, diagnosis and Natural History of Uterine Leiomyoma. Up To Date Online Version 14.1. at www.utdol.com.

2. Tindall VR. Tumours of Corpus Uteri. In; Jeffcoate's Principle of Gynaecology. 5th edition. Butterworths, London; 1987: 417-444.

3. Tumours of Corpus Uteri. In: Textbook of Obstetrics and Gynaecology for Medical Students, second edition. Agboola A (ed). Heinemann Educational Books [Nigeria] Plc. 2006:183-193.

4. Benign Disease of the Uterus and Cervix. In: Gynaecology by Ten Teachers eighteenth edition. Ash Monga (ed). Holder Arnold, London; 2006:103-109.

5. Lumsden MA. Benign Disease of the uterus. In: Dewhurst's Textbook of Obstetrics and Gynaecology for postgraduate. 7th edition. D. Keith Edmonds (ed). Blackwell Scientific Publications, Oxford. 2007: 638-644.
6. Ogedengbe OK: Uterine Fibroids. In: Contemporary Obstetrics and Gynaecology for Developing Countries. Okonofua F and Odunsi K (eds). WHARC, 2003: 202-213.

7. Adelusola KA and Ogunniyi S0: Hysterectomy in Nigerians: Histopathological Analysis of cases seen in Ile-Ife. The Nig PG Medical Journal. 2001; $8[1]: 37-40$.

8. Aboyeji AP and Ijaiya MA. Uterine Fibroids: A Ten-year clinical review in Ilorin, Nigeria, Nig J. Medicine 2002; 11[1]: 16-19.

9. Emembolu J0: Uterine fibromyomata: Presentation and Management in Northern Nigeria. Int. J. Gynaecol. Obstet. 1987; 25: 413 - 416.

10. Ogunniyi S0 and Fasubaa 0B: Uterine Fibromyoma in Ilesa, Nigeria. Nigeria Med. Practitioner, 1990; 19(6): 93-95.

11. Healey D.L. and Vollenhoven B.J. The role of GnRH agonists in the treatment of uterine fibroids. BJOG 1992; 99 (Suppl.7):23-26.

12. Royal College of Radiologists and Royal College of Obstetricians and Gynaecologists. Clinical recommendations on the use of uterine artery embolisation in the management of uterine fibroids. Report of a joint working party of the Royal College of Radiaologists and the Royal College of Obstetrician and Gynaecollogists, London, 2000

13. Ascher SM, Jha RC and Reinhold C[2003]. Benign myometrial conditions:Leiomyomas and Adenomyosis. Top Magn Reson Imag 14[4], 281 304.

14. West CR. Uterine Fibroid. In: Gynaecology. Shaw RW, Soutter WR and Stanton SL (eds). Churchill Livingstone Edinburgh. 1992: 392-410.

15. Friedman AJ, Barbier RC, Benacerraf BR, Schiff I: Treatment of leiomyomata with intranasal or subcutaneous leuprolide a gonadotrophin relasing hormone. Fertility and Sterility. 1987; 48: 560-565.

16. Butram VC. Jr, Reiter RC. Uterine fibromyomata Aetiology, Symptomatology and management. Fertil Steril - 4:36-41. 